\title{
Neovaginal perforation following sexual intercourse in a transsexual patient
}

\author{
Hasan Deliktas ${ }^{1 *}$, Onder Ozcan², Nesat Cullu ${ }^{3}$ and Omer Erdogan
}

\begin{abstract}
Background: Neovaginal perforation can develop following sexual intercourse in patients that have undergone male to female gender reassignment surgery. In such cases urinary tract symptoms may mimic acute cystitis and acute pyelonephritis.

Case presentation: A 33-year old white transsexual patient presented to the emergency department with dysuria, hematuria, difficulty urinating, widespread groin pain, bilateral side pain, clear vaginal discharge, abdominal pain, and nausea 2-3 h after sexual intercourse. Abdominal tomography showed fluid around the vaginal cuff and air throughout the abdomen. Vaginography showed contrast leaking to the abdomen from the vaginal cuff. The patient was considered as vaginal perforation and admitted to clinic.

Conclusion: Vaginal perforation should be considered in transsexual patients that develop urinary system symptoms following sexual intercourse. Such cases were treated medically without the need surgery.
\end{abstract}

Keywords: Neovaginal perforation, Sexual intercourse, Transsexual

\section{Background}

In male to female gender reassignment surgery penile and scrotal skin graft, or the rectosigmoid intestinal segment can be used to create a neovagina $[1,2]$. Creation of a neovagina using penile and scrotal skin graft is associated with more scar tissue and insufficient vaginal cuff length [3,4]; therefore, the likelihood of vaginal perforation following sexual intercourse is elevated in such cases. Herein we present the radiological findings and treatment in a 33-year old gender reassignment surgery patient with vaginal perforation.

\section{Case presentation}

A 33-year old white transsexual patient presented to the emergency department with dysuria, hematuria, difficulty urinating, widespread groin pain, bilateral side pain, clear vaginal discharge, abdominal pain, and nausea $2-3 \mathrm{~h}$ after sexual intercourse. The patient had undergone male to female gender reassignment surgery 7 years earlier, in which penile and scrotal skin graft was used to create a neovagina. Physical examination showed that there was

\footnotetext{
* Correspondence: hasandeliktas@mynet.com

${ }^{1}$ Department of Urology, Mugla Sitki Kocman University, School of Medicine, Mugla 48000, Turkey

Full list of author information is available at the end of the article
}

sensitivity in the suprapubic region, costovertebral angle sensitivity, and defense and rebound.

Laboratory findings included red blood cells $120 \mathrm{u} / \mathrm{L}$ in the full urine test and leukocytes $19 \times 10^{9}$ cells/ $\mathrm{L}$ in the full blood count; other laboratory findings were normal. Abdominal ultrasonography showed fluid around the vaginal cuff and abdominal tomography showed fluid around the vaginal cuff and air throughout the abdomen (Figure 1a and $\mathrm{b}$ ). As vaginal perforation was considered, cystography was performed to search for extravasation originating from the bladder, but extravasation was not observed (Figure 1c). Examination by the gynecology department showed clear discharge localized in the neovagina. A vaginal contrast examination was performed. Vaginography showed contrast leaking to the abdomen from the vaginal cuff (Figure 1d).

The patient's abdominal pain, examination findings, and laboratory findings were evaluated by a specialist general surgeon. The patient was admitted to clinic. As there was no pathology other than vaginal perforation based on abdominal ultrasonography and abdominal tomography, and as the neovagina appeared normal upon vaginal examination, it was thought that with close monitoring the patient would recover and a combination of ceftriaxone $1000 \mathrm{mg}$ b.i.d. and metronidazole $500 \mathrm{mg}$ t.i.d. 

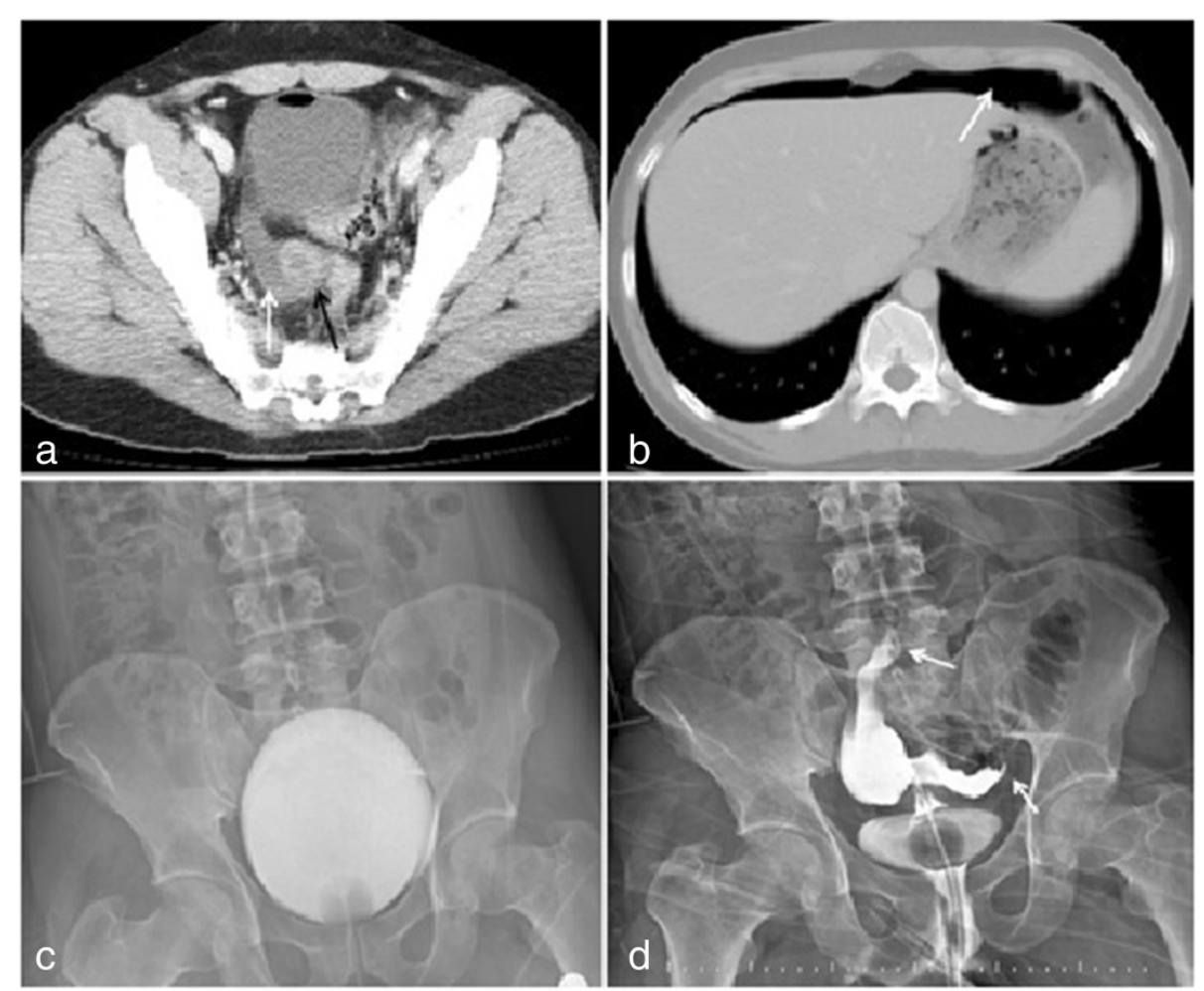

Figure 1 Axial pelvic tomography image; free fluid (white arrow) around the vaginal cuff (black arrow) (a). Axial abdominal tomography image; Free air (white arrow) in the subdiaphragmatic region (b). Cystography image; Contrast extravasation was not observed (c). Vaginography image; Contrast leaking (white arrow) into the abdomen from the vaginal cuff (d).

antibiotherapy was started and continued for $7 \mathrm{~d}$. The patient's abdominal pain became less severe and the fluid discharge from the neovagina stopped. On $\mathrm{d} 4$ of the treatment the leukocyte count returned to normal, and on $\mathrm{d} 7$ of the treatment the patient was discharged with oral antibiotic therapy. At the 1-month follow-up examination the patient was problem-free. At 6 weeks post treatment the patient recommenced sexual intercourse and at the 6-month follow-up had no complaints.

\section{Discussion}

Penile and scrotal skin graft is the most common method for creating a neovagina, as it is associated with the lowest complication rate and is the easiest to perform; however, there are some disadvantages to the method, such as scar formation, an insufficient vaginal cavity, a narrow vaginal, intravaginal hair, the need for continuous dilatation, and the need for lubrication for sexual intercourse [3,4]. The literature includes 2 case reports of neovaginal perforation. Amirian et al. [5] reported a case of neovaginal perforation after washing with a douche pump and Giovanni Liguari et al. [6] reported spontaneous perforation in the neovagina after stenosis. To the best of our knowledge the present case report is the first to describe neovaginal perforation following sexual intercourse. In addition, in the 2 earlier cases the sigmoid colon segment was used for the creation of the neovagina. In the presented case scrotal and penile skin graft was used, and to the best of our knowledge this is the first report of neovaginal perforation in a neovagina formed from scrotal and penile skin graft.

Franco et al. reported that in transsexual individuals in which penile and scrotal skin graft was used neovaginal length was $8-10 \mathrm{~cm}$, which is longer than the natural vagina [7]; however, even with a vagina of $8-10 \mathrm{~cm}$ created using penile and scrotal skin graft the expansion and extension potential of the neovagina in those cases were lower than those of a normal vagina and those created using the sigmoid segment. As such, the likelihood of vaginal perforation during sexual intercourse is higher in such cases. In transsexual surgery sacrospinous ligament fixation of the neovagina is performed in order to prevent prolapse during the postoperative period [8]. By inhibiting the mobilization capability of the neovagina such fixation facilitates perforation during sexual intercourse.

In the presented case there was an indication for laparotomy because of the acute abdominal findings; however, as the patient had undergone surgery 7 years earlier it was 
thought that performing laparotomy again could have resulted in additional complications. Moreover, the neovaginal perforation case reported by Amirian et al. was followed up conservatively and the patient recovered without any surgical intervention [5].

As seen in previous studies on transsexual females in which penile skin was used to create the neovagina, the flora of the neovagina is formed of aerobic and anaerobic microorganisms in the mixed structure found in skin and intestinal flora $[9,10]$. In the presented case administration of antibiotherapy that was effective on both aerobic and anaerobic microorganisms, and close monitoring resulted in complete recovery without the need for surgery.

\section{Conclusion}

In transsexual patients that present with urinary system symptoms following sexual intercourse vaginal perforation should always be a consideration. Minimal perforations in such patients can be treated medically, without surgery.

\section{Consent}

Written informed consent was optained from the patient for publication of this case report and any accompanying images. A copy of the written consent is available for review by the Editor of this journal.

\section{Competing interests}

The authors declare that they have no competing interests.

\section{Authors' contributions}

HD drafted the report. OO, NC and OE cared for patient. All authors reviewed the report and approved final version of the manuscript.

\section{Author details}

${ }^{1}$ Department of Urology, Mugla Sitki Kocman University, School of Medicine, Mugla 48000, Turkey. ${ }^{2}$ Department of Surgery, Mugla Sitki Kocman University, School of Medicine, Mugla, Turkey. ${ }^{3}$ Department of Radiology, Mugla Sitki Kocman University, School of Medicine, Mugla, Turkey.

Received: 23 July 2014 Accepted: 27 October 2014

Published: 15 November 2014

\section{References}

1. van Noort DE, Nicolai JP: Comparison of two methods of vagina construction in transsexuals. Plast Reconstr Surg 1993, 91(7):1308-1315.

2. Dalton JR: Use of sigmoid colon in sex reassignment operations. Urology 1981, 17(3):223-227

3. Perovic SV, Stanojevic DS, Djordjevic ML: Vaginoplasty in male transsexuals using penile skin and a urethral flap. BJU Int 2000, 86(7):843-850.

4. Kwun Kim S, Hoon Park J, Cheol Lee K, Min Park J, Tae Kim J, Chan Kim M: Long-term results in patients after rectosigmoid vaginoplasty. Plast Reconstr Surg 2003, 112(1):143-151.

5. Amirian I, Gogenur I, Rosenberg J: Conservatively treated perforation of the neovagina in a male to female transsexual patient. BMJ Case Rep 2011, 2011.

6. Liguori G, Trombetta C, Buttazzi L, Belgrano E: Acute peritonitis due to introital stenosis and perforation of a bowel neovagina in a transsexual. Obstet Gynecol 2001, 97(5 Pt 2):828-829.

7. Franco T, Miranda LC, Franco D, Zaidhaft S, Aran M: Male-to-female transsexual surgery: experience at the UFRJ University Hospital. Revista do Colegio Brasileiro de Cirurgioes 2010, 37(6):426-434.
8. Stanojevic DS, Djordjevic ML, Milosevic A, Sansalone S, Slavkovic Z, Ducic S, Vujovic S, Perovic SV: Sacrospinous ligament fixation for neovaginal prolapse prevention in male-to-female surgery. Urology 2007, 70(4):767-771.

9. Weyers S, Verstraelen H, Gerris J, Monstrey S, Santiago Gdos S, Saerens B, De Backer E, Claeys G, Vaneechoutte M, Verhelst R: Microflora of the penile skin-lined neovagina of transsexual women. BMC Microbiol 2009, 9:102.

10. Weyers S, Lambein K, Sturtewagen Y, Verstraelen H, Gerris J, Praet M: Cytology of the 'penile' neovagina in transsexual women. Cytopathology 2010, 21(2):111-115

doi:10.1186/1756-0500-7-797

Cite this article as: Deliktas et al:: Neovaginal perforation following sexual intercourse in a transsexual patient. BMC Research Notes 2014 7:797

\section{Submit your next manuscript to BioMed Central and take full advantage of:}

- Convenient online submission

- Thorough peer review

- No space constraints or color figure charges

- Immediate publication on acceptance

- Inclusion in PubMed, CAS, Scopus and Google Scholar

- Research which is freely available for redistribution 